\title{
Correlation between Y chromosome microdeletion and male infertility
}

\author{
X.G. Liu ${ }^{1}$, H.Y. Hü ${ }^{2}$ Y.H. Guo ${ }^{1}$ and Y.P. Sun ${ }^{1}$ \\ ${ }^{1}$ Reproductive Medical Center, \\ The First Affiliated Hospital of Zhengzhou University, Zhengzhou, China \\ ${ }^{2}$ Department of Ultrasound, \\ The Third Affiliated Hospital of Nanyang Medical College, Nanyang, China \\ Corresponding author: Y.P. Sun \\ E-mail: sypsunyp@163.com \\ Genet. Mol. Res. 15 (2): gmr.15028426 \\ Received January 12, 2016 \\ Accepted March 18, 2016 \\ Published June 3, 2016 \\ DOI http://dx.doi.org/10.4238/gmr.15028426
}

\begin{abstract}
Dyszoospermia due to genetic factors is the leading cause of male infertility. To explore the correlation between azoospermia factor (AZF) microdeletion of the Y chromosome and male infertility, we evaluated AZF microdeletion on the long arm of the $\mathrm{Y}$ chromosome in 166 infertile males and 50 fertile males using multiplex polymerase chain reactions amplification and gel electrophoresis. The results demonstrated that 28 individuals had varying degrees of microdeletion in the AZF region $(16.90 \%) ; 12$ out of the 76 males with azoospermia and 16 out of the 90 males with oligospermia had AZF microdeletion. AZF microdeletion was not observed in any of the healthy controls. In addition, $53.60 \%$ of the AZF microdeletions occurred in the AZFc region. It can be concluded that AZF microdeletion on the long arm of the Y chromosome can result in male spermatogenesis dysfunction. Detection of AZF microdeletion can provide a theoretical basis for genetic counseling, as well as improve the diagnosis and treatment of this disease.
\end{abstract}

Key words: Y chromosome; Microdeletion; AZF; Azoospermia; Male infertility 


\section{INTRODUCTION}

Infertility affects 10 to $15 \%$ of childbearing couples, and male infertility accounts for $50 \%$ of these cases. Y chromosome microdeletion is a major pathogenic factor that leads to male sterility (Hucklenbroich et al., 2005; Patrat et al., 2010). Microdeletions can result in varying degrees of dyszoospermia, which ranges from azoospermia to severe oligospermia (Zhu et al., 2007; Martin, 2008). Studies have found that approximately $60 \%$ of Y chromosome microdeletions occur in the AZFc region (Rodovalho et al., 2008; Dai et al., 2015). AZFc deletion can generate diverse clinical phenotypes. It has been shown that two-thirds of infertile males develop azoospermia, of which $50 \%$ of the patients can regain fertility following testicular biopsy; the remaining one-third have oligospermia.

In 1976, Tiepolo and Zuffardi (1976) hypothesized that a gene that could control spermatogenesis is located at the distal end of the long arm of the $\mathrm{Y}$ chromosome. This gene was named as azoospermia factor (AZF). Y chromosome AZF can be further divided into $\mathrm{AZFa}, \mathrm{AZFb}, \mathrm{AZFc}$, and AZFd; microdeletion at any of these sites can lead to dyszoospermia; when $Y$ chromosome microdeletion occurs in any of these four regions, it is referred to as AZF microdeletion (Medica et al., 2005). The incidence of AZFc microdeletion is high, and can lead to diverse clinical outcomes that alter the total count or the structure of sperms. The topic of Y chromosome microdeletions has become a hotspot in scientific research, and is also a challenging field of study both in China and abroad (A et al., 2006; Chen et al., 2010).

Recently, modern molecular biology and cell genetics studies have also confirmed the existence of AZF in the q11 region on the long arm of the Y chromosome (Kleiman et al., 2001). A study (Kleiman et al, 2002) suggested that, 50\% of patients with AZFc deletions could recover fertilization following testis puncture and intracytoplasmic sperm injection (ICSI). Liu et al. (2013) suggested that AZFc deletion is more likely to be passed onto male offsprings, but would not increase the risks of infertility among female offsprings. Patients can choose to undergo preimplantation genetic diagnosis followed by sperm implantation in female embryos. Detection of Y chromosome microdeletion can help determine the causes of infertility in males with non-obstructive azoospermia and moderate-to-severe oligospermia. Furthermore, it can also assist patients in choosing the appropriate assisted reproductive therapy, which is of great significance for the diagnosis and treatment of male infertility. This study selected 166 males with sperm abnormality who received treatments in the First Affiliated Hospital of Zhengzhou University and 50 healthy patients who have undergone Y chromosome AZF microdeletion detection.

\section{MATERIAL AND METHODS}

\section{Clinical data}

We retrospectively analyzed 166 infertile males who were diagnosed and treated at the Andrology Clinic of the Reproductive Center at the First Affiliated Hospital of Zhengzhou University, Henan, China, from February 2010 to February 2014. The patients included had been married for 2 to 13 years, and their wives all had normal reproductive capacity; the patients and their wives had lived together for more than 2 years. Fertilization had not occurred in these cases when no contraception measures were adopted. After strict screening and exclusion of other reasons such as infection, seminal fluid collected from the patients was 
analyzed. According to the seminal fluid analysis criteria of WHO (Mitra et al., 2006), patients whose seminal fluid was found to have no sperm thrice on testing were diagnosed as having azoospermia; those whose sperm concentration was lower than $5 \times 10^{6} / \mathrm{mL}$ were diagnosed as having severe oligospermia. Patients whose seminal fluid showed abnormalities underwent Y chromosome AZF microdeletion detection. Healthy women were used as negative controls and 50 married men whose seminal fluid concentration was higher than $20 \times 10^{6} / \mathrm{mL}$ were used as healthy controls. All research subjects signed the informed consent form. This study follows the ethical principles of assisted reproductive technology of the Ministry of Health and has been approved by the ethics committee of reproductive medicine of the First Affiliated Hospital of Zhengzhou University.

\section{Research methods}

\section{DNA extraction}

Venous blood $(2 \mathrm{~mL})$ was drawn from the patient and collected into an anticoagulation tube. DNA was extracted using the phenyl-chloroform method. The concentration and purity of DNA were detected. DNA concentration was then adjusted to $80-150 \mathrm{ng} / \mu \mathrm{L}$, and was stored at $-20^{\circ} \mathrm{C}$. Patients whose chromosome number was abnormal were not required to undergo AZF gene detection.

\section{Multiplex polymerase chain reaction (PCR)}

The following 15 sequence tag sites (STS) were detected using the Y chromosome microdeletion detection kit provided by Shenzhen Yaneng Biotech: SY82, SY84, and SY86 from the AZFa region; SY124, SY127, SY143, SY134, SY128, and SY133 from the AZFb region; SY254, SY255, SY242, and SY239 from the AZFc region; and SY152 and SY145 from the AZFd region. The 15 STSs were amplified in four tubes with the following colors: purple, white, blue, and yellow. The detailed matching of sample and tubes is detailed in Table 1. Each reaction mixture was composed of $14 \mu \mathrm{L}$ PCR solution, $10 \mu \mathrm{L}$ deionized water, and $1 \mu \mathrm{L}$ DNA. The amplification protocol are as follows: pre-degeneration at $95^{\circ} \mathrm{C}$ for $15 \mathrm{~min}$; degeneration at $95^{\circ} \mathrm{C}$ for $30 \mathrm{~s}$, annealing at $57^{\circ} \mathrm{C}$ for $60 \mathrm{~s}$, extension at $72^{\circ} \mathrm{C}$ for $60 \mathrm{~s}$ for 35 cycles; extension at $72^{\circ} \mathrm{C}$ for $10 \mathrm{~min}$; heat preservation at $4^{\circ} \mathrm{C}$. The sex-determining region on the Y-chromosome SRY gene was used as the internal control. In every test, DNA extracted from married males was taken as the positive control and DNA from healthy females was taken as the negative control.

\section{Detection of amplification product with gel electrophoresis}

PCR products $(10 \mu \mathrm{L})$ were run on $2 \%$ Sepharose gels containing ethidium bromide. The gel was first run at $8 \mathrm{~V} / \mathrm{cm}$ for 3 min until the DNA moved out of the loading gel, after which the voltage was lowered to $4 \mathrm{~V} / \mathrm{cm}$. The duration of electrophoresis was adjusted according to specific conditions. Last, DNA bands visualized using a gel imaging analysis system. 
Table 1. Organization of STS-containing tubes.

\begin{tabular}{l|c|c|c|c|c|c|c}
\hline Tube I (purple) & Site & Tube II (white) & Site & Tube III (blue) & Site & Tube IV (yellow) & Site \\
\hline Internal control & & Internal control & & Internal control & & Internal control & \\
\hline SY254 & C & SY84 & A & SY86 & A & SY134 & B \\
\hline SY143 & B & SY239 & C & SY127 & B & SY82 & A \\
\hline SY242 & C & SY152 & D & SY145 & D & SY128 & B \\
\hline SY255 & C & & & SY124 & B & SY133 & B \\
\hline
\end{tabular}

\section{Judgment of results}

Three independent PCR amplification verifications were performed. If target gene was not amplified, deletion at the site was confirmed.

\section{Statistical analysis}

Experimental data were processed using the SPSS 19.0 software. Comparisons between groups were performed using the Student's $t$-test. Enumeration data were processed by $\chi^{2}$ tests. $\mathrm{P}<0.05$ was denoted as statistically significant.

\section{RESULTS}

\section{PCR amplification products}

Figures 1-3 show electrophoresis results for the products of multiplex PCR amplification. The site lacking the electrophoretic band was the site with deletion of the gene of interest.

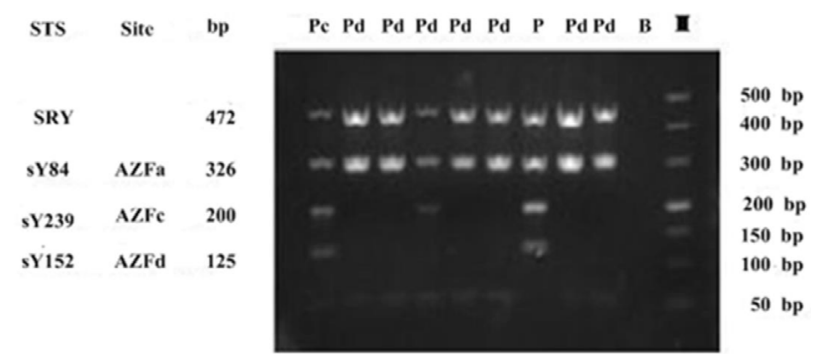

Figure 1. DNA bands for patients with AZFa (sY84), AZFc (sY239), or AZFd (sY152) microdeletions.

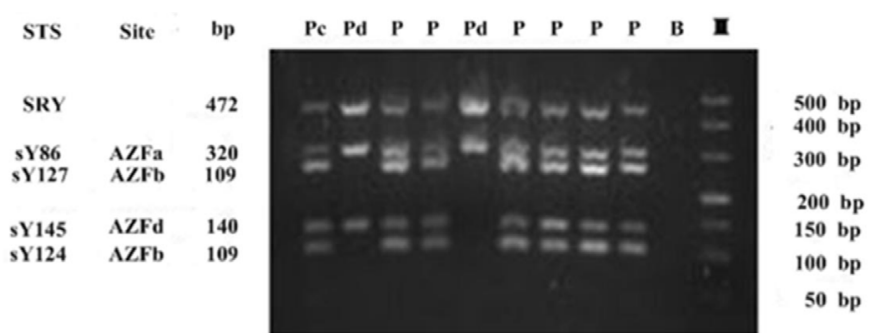

Figure 2. DNA bands for patients with AZFa (sY86), AZFb (sY127, sY124), or AZFc (sY145) microdeletions. 


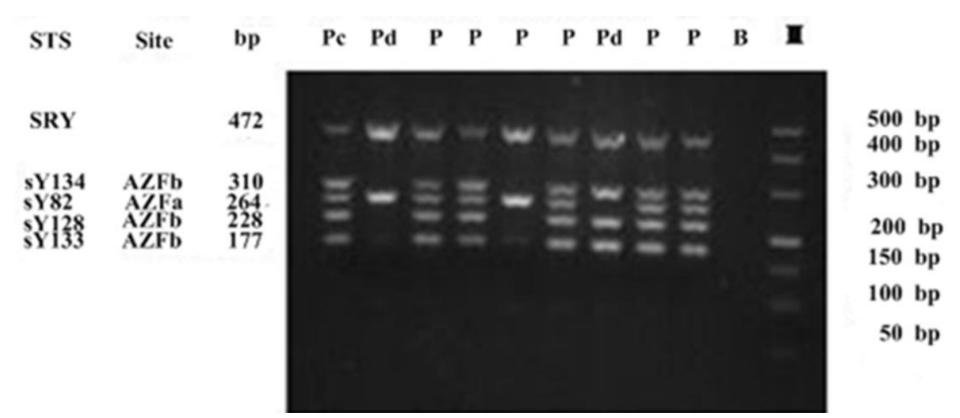

Figure 3. DNA bands for patients with AZFa (sY82) or AZFb (sY128, sY133, sY134) microdeletions.

\section{Y chromosome microdeletion}

In all 50 healthy males, no microdeletion was observed at AZF on the Y chromosome. As expected, DNA from the healthy female controls did not show electrophoretic bands. We found that 28 out of the 166 infertile males (16.9\%), 16 out of the 90 oligospermia patients (17.8\%), and 12 out of the 76 azoospermia (15.8\%) patients had Y chromosome AZF microdeletion. We did not detect any differences in the incidence of Y chromosome microdeletion between patient groups. However, a significant difference in $\mathrm{Y}$ chromosome microdeletion frequency was observed between the healthy control group and the infertile male group $(\mathrm{P}<0.01)$.

The distribution of the different types of AZF microdeletion was as follows: 6 cases of AZFa (21.40\%), 3 cases of AZFb (10.70\%), 15 cases of AZFc (53.60\%), 4 cases of AZFd $(14.30 \%), 3$ cases of AZFa + AZFc (10.70\%), 4 cases of AZFb + AZFc $(14.30 \%), 2$ cases of AZFc + AZFd (7.10\%), and 1 case of AZFb + AZFc + AZFd (3.60\%). The incidence of $\mathrm{AZFc}$ microdeletion was the highest, followed by AZFb + AZFc, AZfa + AZFc, AZFb, AZFc $+\mathrm{AZFd}$, and $\mathrm{AZFb}+\mathrm{AZFc}+\mathrm{AZFd}$. Statistical analysis indicated that the incidence of AZFc microdeletions was much higher as compared to that of AZFb microdeletions $(\mathrm{P}<0.05)$. Details are shown in Table 2.

Table 2. Distribution of the different types of AZF microdeletions $(\mathrm{N})$.

\begin{tabular}{l|c|c|c|c|c|c|c|c}
\hline Clinical performance & AZFa & AZFb & AZFc & AZFd & AZFa+AZFc & AZFb+AZFc & AZFc+AZFd & AZFb+AZFc+AZFd \\
\hline Azoospermia & 0 & 1 & 5 & 2 & 1 & 1 & 1 & 1 \\
\hline Oligospermia & 3 & 2 & 10 & 0 & 2 & 3 & 1 & 0 \\
\hline Total & 3 & 3 & 15 & 2 & 3 & 4 & 2 & 1 \\
\hline
\end{tabular}

\section{DISCUSSION}

A recent research (Benoff et al., 2004) suggests that genetic causes of male infertility include Y chromosome microdeletion, genetic mutation, and single nucleotide polymorphism, as well as chromosomal aberration. Among these, AZF microdeletion is a commonly observed genetic cause that is secondary to Klinefelter syndrome. Shimizu et al. (2002) proposed that approximately $10 \%$ of non-obstructive azoospermia patients are positive for Y chromosome AZF microdeletion. Similarly, Ristanovic et al. (2007) observed high incidence of AZFc microdeletion among patients suffering from severe oligospermia in Serbia. Therefore, 
extensive research has been conducted on azoospermia and severe oligospermia induced by $\mathrm{Y}$ chromosome microdeletions

The incidence of $\mathrm{Y}$ chromosome deletion is $10.8 \%$ among Chinese infertile males, and its incidence among azoospermia and severe oligospermia patients is 11.75 and $8.51 \%$, respectively (Arruda et al., 2007; Li et al., 2015). The AZF site, located on the long arm of the $\mathrm{Y}$ chromosome, contains a large number of microdeletions. AZF microdeletions can result in various spermatogenic disorders and thus induce infertility. There are four sub-areas in AZF: AZFa, AZFb, AZFc, and AZFd; microdeletion in different areas can lead to different clinical outcomes (Jiang et al., 1999; Dada et al., 2011). AZFa microdeletions generally lead to azoospermia and small testicular volume; AZFb microdeletions result in termination of sperm production; AZFc microdeletions can produce a small quantity of active sperms and a large number of abnormal sperms; and AZFd microdeletions leads to mild oligospermia, where a normal number of sperms is produced, but the sperms show abnormal form. Several studies (Chiang et al., 2000; Dohle et al., 2002) have found that $60 \%$ of Y chromosome microdeletions occur in AFCs. The results obtained in the current study suggest that 15 out of 28 cases of AZF microdeletions were AZFc microdeletions, (53.60\%), which is consistent with previous findings (Chiang et al., 2000; Dohle et al., 2002).

With the development of sperm acquisition technology and ICSI, some AZFc microdeletion patients can recover and successfully fertilize their female partners via ICSI. Choi et al. (2013) previously performed testicular needle aspirations on 21 azoospermia patients who had AZFc microdeletions. The sperms that satisfied the quality standard for ICSI were successively acquired from 8 patients (38\%). AZF may be passed onto the next male generation; hence, it is beneficial to label specific DNA sequences on the Y chromosome, perform PCR screening for patients with severe oligospermia and azoospermia, perform preimplantation genetic diagnosis for patients with microdeletion, and ensure that sperms are only implanted into female embryos (Foresta et al., 2001). Additionally, determination of spermatogenetic failures at the molecular level can avoid unnecessary treatments, which can reduce economic burden and pain for patients.

In this study, 166 infertile males underwent $\mathrm{Y}$ chromosome microdeletion analysis. Twenty-eight patients had Y chromosome microdeletions (16.90\%): 16 of the 90 cases of severe oligospermia and 12 of the 76 cases of non-obstructive azoospermia. No significant difference in the rate of incidence was detected between these two groups. Among the 28 cases of $Y$ chromosome microdeletion, different types of microdeletions were observed; these included $\mathrm{AZFb}$ microdeletions, $\mathrm{AZFc}$ microdeletions, $\mathrm{AZFa}+\mathrm{AZFc}$ microdeletions, $\mathrm{AZFc}$ $+\mathrm{AZFd}$ microdeletions, and $\mathrm{AZFb}+\mathrm{AZFc}+\mathrm{AZFd}$ microdeletion. AZFc microdeletion had the highest incidence rate. The incidence rates of AZF microdeletions in patients with severe oligospermia and azoospermia were similar.

This study has shown that $\mathrm{Y}$ chromosome microdeletion is a major genetic cause of primary male infertility. Detection of $\mathrm{Y}$ chromosome microdeletions is of great use for guiding clinical diagnosis, helping selecting treatment schemes, and reducing the incidence of this genetic disease. Therefore, Y chromosome microdeletion examinations are needed before formulation of the treatment protocol for infertile patients with abnormal sperms.

In this study, the sample size and the number of genetic loci were limited. To better understand the pathogenesis of male infertility, studies with larger sample sizes and more genetic loci need to be carried out. 


\section{Conflicts of interest}

The authors declare no conflict of interest.

\section{ACKNOWLEDGMENTS}

The authors sincerely thank all who supported this research.

\section{REFERENCES}

A ZC, Yang Y, Zhang SZ, Zhang W, et al. (2006). Chromosomal abnormality and Y chromosome microdeletion in Chinese patients with azoospermia or severe oligozoospermia. Yi Chuan Xue Bao 33: 111-116. http://dx.doi.org/10.1016/ $\underline{\mathrm{S} 0379-4172(06) 60029-2}$

Arruda JT, Bordin BM, Santos PR, Mesquita WE, et al. (2007). Y chromosome microdeletions in Brazilian fertility clinic patients. Genet. Mol. Res. 6: 461-469.

Benoff SH, Millan C, Hurley IR, Napolitano B, et al. (2004). Bilateral increased apoptosis and bilateral accumulation of cadmium in infertile men with left varicocele. Hum. Reprod. 19: 616-627.http://dx.doi.org/10.1093/humrep/deh139

Chen Y, Wang ZW, Wang ZF, Lin JW, et al. (2010). Cytogenetic and molecular genetic analysis of 335 patients with azoospermia and severe oligozoospermia. Chin. J. Androl 24: 42-45.

Chiang HS, Wei HJ and Chen YT (2000). Genetic screening for patients with azoospermia and severe oligo-asthenospermia. Int. J. Androl. 23 (Suppl 2): 20-25.http://dx.doi.org/10.1046/j.1365-2605.2000.00006.x

Choi DK, Gong IH, Hwang JH, Oh JJ, et al. (2013). Detection of Y chromosome microdeletion is valuable in the treatment of patients with nonobstructive azoospermia and oligoasthenoteratozoospermia: sperm retrieval rate and birth rate. Korean J. Urol. 54: 111-116. http://dx.doi.org/10.4111/kju.2013.54.2.111

Dada R, Gupta NP and Kucheria K (2002). AZF microdeletions associated with idiopathic and non-idiopathic cases with cryptorchidism and varicocele. Asian J. Androl. 4: 259-263.

Dai RL, Hou Y, Li FB, Yue JM, et al. (2015). Varicocele and male infertility in Northeast China: Y chromosome microdeletion as an underlying cause. Genet. Mol. Res. 14: 6583-6590. http://dx.doi.org/10.4238/2015.June.12.13

Dohle GR, Halley DJ, Van Hemel JO, van den Ouwel AM, et al. (2002). Genetic risk factors in infertile men with severe oligozoospermia and azoospermia. Hum. Reprod. 17: 13-16. http://dx.doi.org/10.1093/humrep/17.1.13

Foresta C, Moro E and Ferlin A (2001). Prognostic value of Y deletion analysis. The role of current methods. Hum. Reprod. 16: 1543-1547.http://dx.doi.org/10.1093/humrep/16.8.1543

Hucklenbroich K, Gromoll J, Heinrich M, Hohoff C, et al. (2005). Partial deletions in the AZFc region of the Y chromosome occur in men with impaired as well as normal spermatogenesis. Hum. Reprod. 20: 191-197. http:// dx.doi.org/10.1093/humrep/deh558

Jiang MC, Lien YR, Chen SU, Ko TM, et al. (1999). Transmission of de novo mutations of the deleted in azoospermia genes from a severely oligozoospermic male to a son via intracytoplasmic sperm injection. Fertil. Steril. 71: 10291032.http://dx.doi.org/10.1016/S0015-0282(99)00150-8

Kleiman SE, Lagziel A, Yogev L, Botchan A, et al. (2001). Expression of CDY1 may identify complete spermatogenesis. Fertil. Steril. 75: 166-173. http://dx.doi.org/10.1016/S0015-0282(00)01639-3

Kleiman SE, Yogev L, Paz G and Yavetz H (2002). [The prognostic value of the site and extent of Y chromosome microdeletions on spermatogenesis]. Harefuah 141: 178-180, 222, 221.

Li LX, Dai HY, Ding XP, Zhang YP, et al. (2015). Investigation of AZF microdeletions in patients with Klinefelter syndrome. Genet. Mol. Res. 14: 15140-15147. http://dx.doi.org/10.4238/2015.November.25.2

Liu XH, Qiao J, Li R, Yan LY, et al. (2013). Y chromosome AZFc microdeletion may not affect the outcomes of ICSI for infertile males with fresh ejaculated sperm. J. Assist. Reprod. Genet. 30: 813-819. http://dx.doi.org/10.1007/ $\underline{\text { s10815-013-0009-y }}$

Martin RH (2008). Cytogenetic determinants of male fertility. Hum. Reprod. Update 14: 379-390. http://dx.doi. org/10.1093/humupd/dmn017

Medica I, Gligorievska N, Prenc M and Peterlin B (2005). Y microdeletions in the Istria county, Croatia. Asian J. Androl. 7: 213-216. http://dx.doi.org/10.1111/j.1745-7262.2005.00028.x

Mitra A, Dada R, Kumar R, Gupta NP, et al. (2006). Y chromosome microdeletions in azoospermic patients with Klinefelter's syndrome. Asian J. Androl. 8: 81-88. http://dx.doi.org/10.1111/j.1745-7262.2006.00083.x 
Patrat C, Bienvenu T, Janny L, Faure AK, et al. (2010). Clinical data and parenthood of 63 infertile and Y-microdeleted men. Fertil. Steril. 93: 822-832. http://dx.doi.org/10.1016/j.fertnstert.2008.10.033

Ristanovic M, Bunjevacki V, Tulic C, Novakovic I, et al. (2007). Prevalence of Y chromosome microdeletions in infertile men with severe oligozoospermia in Serbia. Genet. Couns. 18: 337-342.

Rodovalho RG, Arruda JT and Moura KK (2008). Tracking microdeletions of the AZF region in a patrilineal line of infertile men. Genet. Mol. Res. 7: 614-622. http://dx.doi.org/10.4238/vol7-3gmr455

Shimizu A, Ichikawa T, Suzuki N, Yamazaki T, et al. (2002). Microdeletions in the Y chromosome of patients with idiopathic azoospermia. Asian J. Androl. 4: 111-115.

Tiepolo L and Zuffardi O (1976). Localization of factors controlling spermatogenesis in the nonfluorescent portion of the human Y chromosome long arm. Hum. Genet. 34: 119-124. http://dx.doi.org/10.1007/BF00278879

Zhu XB, Li Z, Guo AL, Cao XR, et al. (2007). [Study on the vertical transmission of Y chromosome microdeletions from father to son]. Zhonghua Yi Xue Yi Chuan Xue Za Zhi 24: 203-205. 